\title{
Health-related quality of life of women with nausea and vomiting in pregnancy attending a maternal clinic in Nigeria
}

\author{
Ahwinahwi Ufuoma Shalom, ${ }^{1}$ Odili Valentine Uche, ${ }^{2}$ Elumelu Sabina ${ }^{1}$ \\ 1. Department of Clinical pharmacy and pharmacy administration, Delta State University, Abraka - Nigeria \\ 2. Department of Clinical pharmacy and pharmacy practice, University of Benin, Benin-city, Nigeria
}

\begin{abstract}
Purpose: This study evaluated the health related quality of life of women with nausea and vomiting of pregnancy attending a maternal clinic in Nigeria Methods: A cross-sectional study was conducted on women with nausea and vomiting of pregnancy(NVP) attending ante-natal clinic at a secondary health facility. The NVP-specific quality of life questionnaire developed for women within 12 weeks of pregnancy was used in this study with some modifications. A total number of 119 women made up the study sample. Data was analyzed using SPSS version 20.Mean scores were presented with standard deviations and domain scores were compared using the mean transformed scores. Results: One hundred and nineteen pregnant women who had NVP at the time of the study participated in the study. The mean total quality of life score was $112.16 \pm 33.3$ and $53.7 \%$ had an average quality of life. Domains on Limitation had a mean transformed score of 27.90 while domain on Fatigue had a mean transformed score of 50.94 depicting better and worse quality of life respectively.Conclusion: The findings showed that women in this locality were able to carry out their normal daily activity irrespective of the impact of nausea and vomiting on them.Members of the healthcare team should however work at improving the quality of life of women with NVP in this locality.
\end{abstract}

Keywords: Health -related quality of life, Nausea, Pregnancy, Vomiting,

\section{INTRODUCTION}

It is estimated that $70-80 \%$ of pregnant women experience nausea and vomiting ${ }^{[1]}$. In the United States and Canada, this translates to 4,000,000 and 350,000 women respectively ${ }^{[2]}$. A study has also reported a prevalence of $43.7 \%$ for nausea and vomiting in pregnancy among Nigerian women ${ }^{[3]}$. Nausea and vomiting associated with pregnancy could affect the quality of a woman's life. Health-related quality of life (HRQOL) has been defined as an individual's functional experience of disease and treatment-related symptoms ${ }^{[4]}$. A woman's perspective of her ability to maintain her expected level of function for personal, household and social responsibilities while confronting illness is now recognized as an important dimension of the quality of medical care $^{[5]}$.Existing literature suggests that women with uncomplicated pregnancies experience functional changes that can alter their ability to carry out their usual roles and diminish their quality of life ${ }^{[6],[7]}$, and this is likely reflective of the physical demands of pregnancy on the body ${ }^{[8]}$. Moreover, the decreased HRQOL experienced routinely by pregnant women may, in part, be attributed to the impact of nausea and vomiting of pregnancy $(\mathrm{NVP})^{[9],[10],[1],[12]}$. Nausea and vomiting of pregnancy not only affects the physical health of pregnant women, but can also negatively impact their family, social and occupational functioning ${ }^{[13],[14]}$. Furthermore, the degree of this negative impact seems to be associated with the severity of $\mathrm{NVP}^{[10],[15]}$.Severe and intractable NVP, hyperemesis gravidarum $(\mathrm{HG})$, occurs in approximately $0.5-2 \%$ of pregnancies ${ }^{[16]}$, and studies specific to HG have also detailed the significant physical, psychological, social and economic toll ${ }^{[17],[18]}$. Health related quality of life measures the burden of illness. Ware's conceptual model of HRQOL recognizes that a given health condition, in this case NVP, causes both physical and mental symptoms, and that the impact of these symptoms on HRQOL must be viewed within a social, or participatory context ${ }^{[19]}$.

Both generic and disease-specific HRQOL instruments have been developed to facilitate the assessment of physical and psychosocial components of patients' well-being and functioning using their selfreports ${ }^{[20]}$. Taking advantage of both generic and disease-specific tools may help better understand the impact of NVP on HRQOL ${ }^{[21]}$. A condition-specific instrument for NVP HRQOL assessment (NVPQOL) was developed by Magee et $\mathrm{al}^{[22]}$, and was further validated by Lacasse and Berard ${ }^{[23]}$. Pregnant women with NVP seem to have lower SF36 scores when compared with asymptomatic pregnant women ${ }^{[12]}$, and women with severe or moderate NVP have lower NVPQOL scores when compared with those with mild NVP ${ }^{[10]}$.

The only existing NVP-specific QOL questionnaire, found from our search of literature is the "HealthRelated Quality of Life for Nausea and Vomiting during Pregnancy" (NVPQOL) ${ }^{[22]}$, which was developed for women in their first trimester of pregnancy.The NVPQOL questionnaire measures QOL in the last week and contains 30 items covering 4 general domains: physical symptoms and aggravating factors, fatigue, emotions, and limitations ${ }^{[22]}$. 
Although the prevalence of NVP in Nigeria is high ${ }^{[3]}$, studies on its effect on the quality of life of Nigerian women are scarce in literature. This study therefore aims to determine the effect of NVP on the health related quality of life of Nigerian women.

\section{Study Design}

\section{METHODS}

This was a cross-sectional prospective study to evaluate the health-related quality of life of women with nausea and vomiting of pregnancy attending a maternal clinic at Central Hospital, Agbor; Delta State Nigeria.

Setting

Central Hospital, Agbor is secondary health facility, situated in the northern senatorial district of Delta State in southern Nigeria. People from neighboring communities also attend this centre as this is the only one of such facilities in the locality. Antenatal clinics are held on Mondays, Tuesdays and Wednesdays. Pregnant women who attend the clinic for the first time come in on Wednesdays and those who have attended at some time earlier come on Mondays and Tuesdays. The Facility is able to register only fifty new pregnant women every week.

\section{Population and Sample}

Fifty women are freshly registered at the center on a weekly basis and the study was conducted for 8 weeks and this gave a total population of 400 . Using the Raosoft ${ }^{\circledR}$ sample size calculator and a $5 \%$ margin of error, at $95 \%$ confidence level and 50\% response distribution, a sample size of 197 was calculated. However, the questionnaire was administered to a total of 300 women.

\section{Instrument}

A nausea and vomiting in pregnancy (NVP) specific quality of life questionnaire developed by Maggie et al ${ }^{[22]}$ and validated by Lacasse and Berard ${ }^{[23]}$ was used for the study. The questionnaire was pre-tested using pregnant women in another community in Delta state. Although the NVP - specific questionnaire developed by Maggie et al was specifically developed for women in their first trimester of pregnancy, its use was modified in our study because of the peculiarities in our locality. It was observed that most women in their first trimester did not attend antenatal clinic until second or third trimester and hence its use for all pregnant women having NVP at the time of the study. A socio-demographic section which included items like age, marital status, educational level, ethnic group and maternal characteristics e.t.c. was added to the NVP-specific quality of life questionnaire. The NVP specific quality of life questionnaire contains 30 items which represent four domains with each item set on a 7-point Likert scale. The scoring and descriptions of the various domains are as described by Maggee et al. (These domains are Physical symptoms/aggravating factors, Fatigue, Emotions and Limitations.

\section{DATA COLLECTION}

Respondents were informed of the benefits of the research and an oral informed consent was obtained before the questionnaires were filled. A researcher-patient interview was conducted with the administration of the questionnaire during the period of the study. The socio-demographic data of all consenting pregnant women was first obtained. Respondents who were either ill and/or on medications were excluded from the study since these factors could induce nausea and vomiting. Respondents who had nausea and vomiting of pregnancy at the time of the study were further interviewed using the NVP-specific quality of life questionnaire. The questions were read out and explained to the respondents by trained interviewers. It took an average of 2 minutes to complete the questionnaire for those who did not have NVP at the time of the study. For those who still had NVP and experienced it in the past week, it took an average of 5 minutes to complete the questionnaire. For those who did not understand English language, the questions were read out and explained to them in vernacular.

\section{Ethical Consideration}

The study was carried out after approval was obtained from the administrative office of the hospital prior to the commencement of the study. Relevant guidelines for maintaining the confidentiality of information were strictly spelt out and adhered to. The questionnaire was administered after an oral informed consent was obtained from the respondents.

\section{Data Analysis}

Data was analyzed using SPSS version 20. Descriptive statistics was used to estimate the distribution of maternal characteristics and health related quality of life scores in the study population. The overall quality of life scores was measured by summing the 30 items which ranged from 30-210. Lower scores correspond to better quality of life. The quality of life scores for the different domains were also obtained by summing the 
scores of the items which represent the different domains and in order to obtain a standard for comparison between the different domains; these summed scores were transformed using (1)

Transformed Score $=$ Actual raw score - lowest possible score $\times 100$

$$
\text { Possible raw score range }
$$

\section{RESULTS}

Out of the 300 women that participated in the study, 54 did not have nausea and vomiting in the current pregnancy, a total of 127 had nausea and vomiting at a time earlier than when the study was conducted while 119 had nausea and vomiting at the time of the study. The One hundred and nineteen women who had NVP at the time of the study made up the study population and were administered the NVPQOL specific questionnaire. Overall, the respondents with NVP were aged 15 to 44 years. Majority of the respondents $44(36.9 \%)$ were in the age range of 21-26 years, were married 105 (88.2\%) and had a tertiary level education 53 (44.5\%). Other demographic details are shown in Table 1.

Table 1. Socio demographics of the respondents

\begin{tabular}{|c|c|c|}
\hline Characteristics & Frequency & $\begin{array}{l}\text { Percentage } \\
(\%)\end{array}$ \\
\hline \multicolumn{3}{|l|}{ Age (Years) } \\
\hline $15-20$ & 10 & 8.4 \\
\hline 21-26 & 44 & 36.9 \\
\hline 27-32 & 39 & 32.8 \\
\hline 33-38 & 24 & 20.2 \\
\hline $39-44$ & 2 & 1.7 \\
\hline \multicolumn{3}{|l|}{ Marital status } \\
\hline Single & 13 & 10.9 \\
\hline Married & 105 & 88.2 \\
\hline Divorced/Separated & 1 & 0.8 \\
\hline \multicolumn{3}{|l|}{ Level of Education } \\
\hline No basic education & 3 & 2.5 \\
\hline Primary education & 19 & 15.9 \\
\hline Secondary education & 41 & 34.5 \\
\hline Tertiary education & 53 & 44.5 \\
\hline No response & 3 & 2.5 \\
\hline \multicolumn{3}{|l|}{ Employment status } \\
\hline Student & 13 & 10.9 \\
\hline Housewife & 28 & 23.5 \\
\hline Unemployed & 14 & 11.8 \\
\hline Trader & 29 & 24.4 \\
\hline Public servant & 19 & 15.9 \\
\hline Artisan & 14 & 11.8 \\
\hline Others & 2 & 1.7 \\
\hline
\end{tabular}

Most of the women, 35 (29.7\%) had a gravidity of 2 while just $13(10.9 \%)$ had a gravidity of 5 and above. Majority $78(65.5 \%)$ were at a gestational age of 13-24 weeks at the time of first visit or ante-natal care. Other details of the gestational characteristics are shown in Table 2. 
Table 2: Gestational characteristics of the respondents

\begin{tabular}{lll}
\hline \multicolumn{1}{c}{ Characteristics } & Frequency & Percentage \\
\hline Gravidity & 17 & 13.4 \\
1 & 30 & 23.6 \\
2 & 40 & 31.5 \\
3 & 24 & 18.9 \\
4 & 16 & 12.6 \\
5 \& above & & \\
Number of pregnancies to full & & \\
term & 26 & 20.5 \\
0 & 35 & 27.5 \\
1 & 35 & 27.5 \\
2 & 23 & 18.1 \\
3 & 7 & 5.5 \\
4 & 1 & 0.8 \\
5 \& above & & 3.1 \\
Age of gestation & 4 & 30.7 \\
$0-12$ & 39 & 66.7 \\
$13-24$ & 84 & \\
$25 \&$ above & & \\
\hline
\end{tabular}

The mean total score for the NVPQOL of the study population was $112.16(\mathrm{SD}=33.3$ and range $=62-184)$. The lowest mean quality of life score indicating higher quality of life was recorded in the gestational age group 25 weeks and above, who had a score of $109.1 \pm 39.3$ while the highest score of $114.5 \pm 34.57$ indicating poorer quality of life was recorded in the gestational age range 0-12 weeks. Other details are shown in Table 3 below.

Table 3: Quality of life scores for the respondents

\begin{tabular}{llllll}
\hline GESTATIONAL & FREQUENCY & TOTAL & MEAN & STANDARD & P- \\
AGE $($ WEEKS) & & SCORE & SCORE & DEVIATION & VALUES \\
\hline $\mathbf{0 - 1 2}$ & 6 & 687 & 114.5 & \pm 34.57 & $>0.10$ \\
$13-24$ & 91 & 10272 & 112.9 & \pm 26.10 & 0.0080 \\
$25 \&$ above & 22 & 2401 & 109.1 & \pm 39.3 & $>0.10$ \\
\hline
\end{tabular}

Each domain had different number of items, therefore the scores were transformed to obtain a basis for comparison. Since lower scores indicate better quality of life, the respondents gave the worst ratings to the domains "fatigue" and "physical symptoms and aggravating factors". Other details are shown in Table 4 below.

Table 4.Quality of life scores for the respondents based on the different domains

\begin{tabular}{|c|c|c|c|}
\hline Domains & $\begin{array}{l}\text { Number } \\
\text { Of items }\end{array}$ & $\begin{array}{l}\text { Mean domain raw } \\
\text { score }\end{array}$ & $\begin{array}{l}\text { Mean domain } \\
\text { transformed score }\end{array}$ \\
\hline Physical symptoms & 9 & 35.44 & 49.01 \\
\hline Fatigue & 4 & 16.23 & 50.94 \\
\hline Emotions & 7 & 25.38 & 43.82 \\
\hline Limitations & 10 & 35.11 & 27.90 \\
\hline
\end{tabular}

The overall quality of life scores obtained for the participants based on gestational age showed that about fifty four percent of the respondents had their overall quality of life rated as average. Other quality of life assessments are as shown in fig. 1 . 


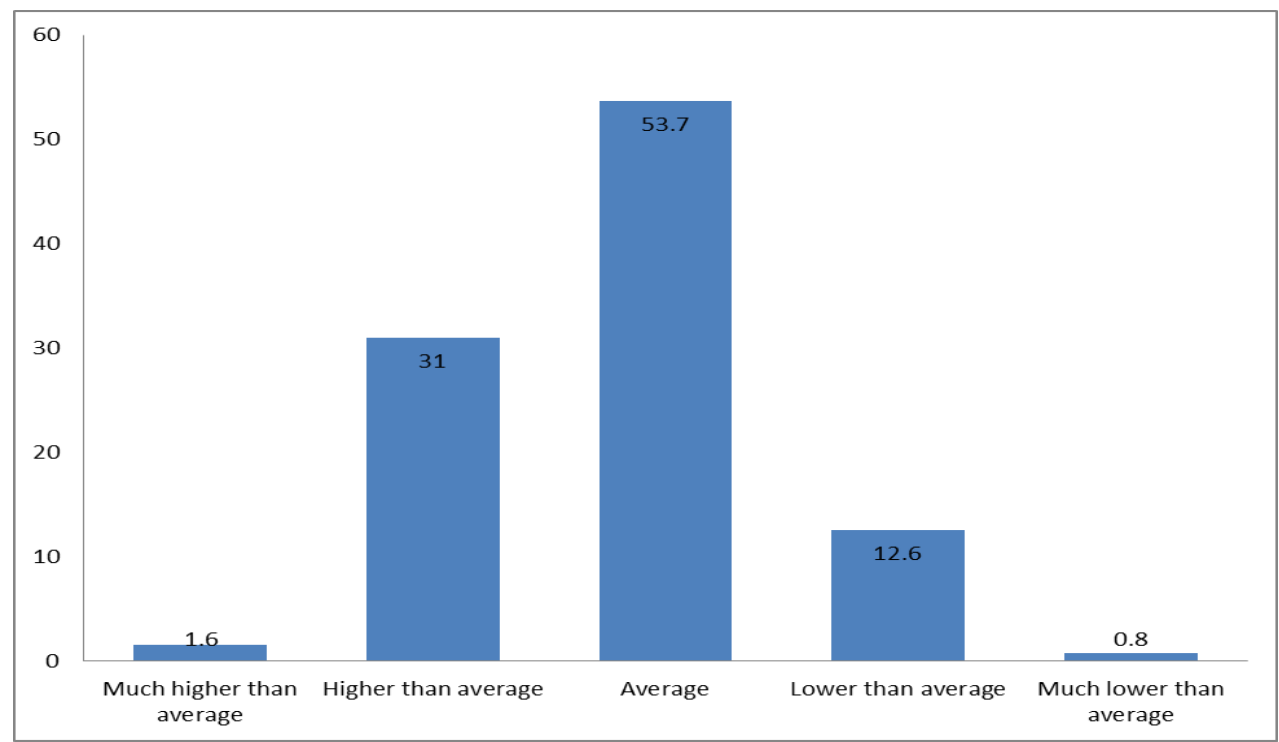

Fig. 1 Overall quality of life assessment with NVPQOL questionnaire.

\section{DISCUSSION}

This study evaluated the quality of life of nausea and vomiting in pregnant women using the NVP-specific quality of life questionnaire. Four domains namely, physical symptoms and aggravating factors, fatigue, emotions and limitations were evaluated. The mean total quality of life of the respondents was average with over half of the population actually having an average quality of life rating this corroborates the findings of Balikova and Buzgova ${ }^{[24]}$ whose study sample had an average quality of life rating as measured by the NVPspecific questionnaire. In this study, pregnant women in their first trimester had higher NVP-scores indicating worse quality of life, the findings of a previous study ${ }^{[25]}$ reported that severe NVP was associated with poorer quality of life, this indicates that NVP was more severe in women in their first trimester of pregnancy when compared with the others. Similarly, Lacasse (2008) claimed that NVP has a negative impact on QOL stressing the need for optimal care of patients with nausea and vomiting during their pregnancy.Women in the gestational age range 25 weeks and above had a better quality of life since they had lower scores while women in the gestational age range 0-12 weeks had a lower quality of life since they had higher scores.It can thus be said that the quality of life of women with NVP can be influenced by the duration of pregnancy. In comparison with a previous study ${ }^{[24]}$, the QOL of women with NVP and pregnancy lasting up to 12 weeks was lower than in those with pregnancies that lasted more than 12 weeks. Lacasse and Berard ${ }^{[23]}$ reported older gestational age to be one of the characteristics associated with a higher QOL. There was a statistically significant association between the quality of life and gestational age at weeks 13-24.The respondents gave the best ratings to the domain "Limitation" while the worst was the domain "fatigue" this means that despite the impact of NVP on their quality of life they are able to carry out their normal tasks. As seen from the study most of the women who participated in the study had one form of employment or the other this could also be responsible for the drive to carry out their activities irrespective of fatigue or other impact of NVP on their quality of life; in a previous study, the domain "fatigue" also got worst ratings by women with NVP ${ }^{[24]}$.

\section{CONCLUSION}

This study evaluated the health-related quality of women with NVP to be moderate. Women studied carried out their routine tasks to a large extent. Members of the healthcare team should therefore devise means to improve on the quality of life of women in this locality.

\section{REFERENCES}

[1] O'Brien and Zhou Q.Variables related nausea and vomiting during pregnancy. Birth 22, 1995,93-100

[2] Mazzotta P, Steward D, Atanaclovic G, Koren G, Magee LA. Psychosocial morbidity among women with nausea and vomiting: prevalence and association with antiemetic therapy. J Psychosom Obstet Gynecol 21,2000 ; 129-136

[3] Wodi C, Danborno B, Adebisi S.S, Eze UA. Incidence of nausea and vomiting in pregnancy among Nigerian women. Sch.J.App Med Sc 2(10), 2014, 413-421

[4] Khanna D, Tsevat J. Health -related quality of life: An introduction . Am J Manag Care. 13, 2007, S218S223

[5] Geigle r, jones SB. Outcomes measurement: A report from the front, Inquiry 27(1), 1990, 7-13 
[6] Gjerdingen DK, Froberg DG, FontaineP. The effects of social support on women's health during pregnancy, labour and delivery, and the postpartum period. Fam Med 23,1991, 370-375

[7] Hueston $\mathrm{Wj}$, Kasik-Miller S. Change in functional health status during normal pregnancy. J Fam Pract 47, 1998, 209-212

[8] Mota N, cox BJ, Enns MW, Calhoun L, Saren J. The relationship between mental disorders , quality of life and pregnancy : findings from a nationally representative sample. J Affect Disord 109(3), 2008,300304

[9] Smith C, Crowtherc, Beilby J, Dandeaus J. the impact of nausea and vomiting on women : a burden of early pregnancy . Aust NZ J Obstet Gynaecol 40(4), 2000, 397-401

[10] Lacasse A, Rey E, Ferreira E, Morin C, Berard A. Nausea and vomiting of pregnancy : what about quality of life? BJOG 115, 2008, 1484-1493

[11] Kugahara T , Ohashi k. characteristics of nausea and vomiting in pregnant Japanese women. Nurs health Sci 8(3), 2006, 179-184

[12] Attard CL, Kohli MA Coleman S, Bradley C, Hux M, Atanaclovic G, Torrance GW. The burden of illness of severe nausea and vomiting of pregnancy in the United States. Am J Obstet Gynecol 103, 2004,803-811

[13] Chou FH, Chen CH, Kuo SH, Tzeng YL, Experience of Taiwanese women living with nausea and vomiting during pregnancy . Journal Midwifery Womens' Health 51(5), 2006, 370-375

[14] LocockL, Alexander J, Rozmovits L. Women's responses to nausea and vomiting in pregnancy. Midwifery 24(2), 2008, 143-152

[15] O'Brien B , Naber S. nausea and vomiting during pregnancy; Effects on the quality of women's lives. Birth 19(3) , 138-143

[16] American College of Obstericians and Gynecologist. ACOGpractice bulletin . Clinical management guidelines for Obsttrician-ngynecologists: nausea and vomiting of pregnancy. Obstet Gynecol 186, 2002, S220- S227

[17] O'Brien B, Relyea J, Lidstone T. Diary reports of nausea and vomiting during pregnancy Nurs Res 6(3) ,1997,239-252

[18] MeighanM, Wood AF. The impact of hyperemesis gravidarum on maternal role assumption . J Obstet Gynecol Neonatal Nurs 34 (2), 2005, 172-179.

[19] Ware JE Jr, Kosinski M, Gandek B. S.F 36 Health Survey : Manual 7 Interpretation Guide . Quality / Metric Incorporated ; Lincoln RI, USA: 2000. Ware JE., . Conceptualization and measurementof healthrelated quality pf lif : comments on an evolving field. Arch Phys Mes Rehab. 84(Suppl 2), 2003, S\$43S51

[20] Gringeri A, von mackensen S. quality of life in heamophilia. Heamophilia 14(Suppl3),2008, 19-25

[21] Agren, Berg M. tactile massage and severe nausea and vomiting during pregnancy women's experiences . Scand J Caring Sci 20, 2006, 169-176

[22] Maggee LA, Chandra K, Mazzotta P, Stewart D, Koren G, Guyatt GH. Develo[ment of a health -related quality of life instrument for nausea and vomiting of pregnancy . Am J Obstet Gynecol 186, 2002, S232S238

[23] Lacasse A, Berard A. A validation of the nausea and vomiting of pregnancy specific quality of life questionnaire. Health and Quality of Life Outcomes 32(6), 2008

[24] Balikova,m , Buzgova r, Quality of women's life with nausea and vomiting during pregnancy. Osetrovatelstvi a porodni asistence 5(1),2014,29-35

[25] Naeimi rad M, Lamyian M. Quality of life in women with nausea and vomiting from pregnancy. Caspian J Reprod Med. 1 (3), 2015 ,18-21 